\title{
Poisoning in Korean Children and Adolescents
}

\author{
Jae Hyug Woo and Eell Ryoo* \\ Departments of Emergency Medicine and *Pediatrics, Gil Medical Center, Gachon University Graduate School of \\ Medicine, Incheon, Korea
}

\begin{abstract}
Drug intoxication in children and adolescents is not uncommon in Korea. But the tendency of intoxication is changing with some factors, such as national surveillance system, Naderism and increasing concern among physicians. But the death rate of intoxication among adolescents is increasing in spite of decreasing total death rate of intoxication among children and adolescents. Therefore the physician must be concerned about the basic management of intoxication and figure out the common toxic substance among children and adolescents.
\end{abstract}

Key Words: Poisoning, Child, Adolescent, Drug overdose, Korea

\section{INTRODUCTION}

Younger children are vulnerable to unintentional poisoning, whereas adolescence is critical age for intoxication by intentional drug ingestion. In the past, one of the confusing forms of intoxication to inexperienced physicians was the ingestion of liquid mercury from broken mercury thermometer. And the notorious toxic herbicide, 'paraquat (Gramoxone; SYNGENTA Korea, Seoul, Korea)', was a major worry to Korean physicians in emergency rooms in the past, but this concern has disappeared since its removal from the market in Korea in 2011.

The term 'toxicology' is a word derived from the Greek term, 'toxikos' and 'toxikon', which each means bow and poison into which arrowheads are dipped [1]. The term 'poisoning' usually means the physiological state led by medicine, and the term 'intoxication' has wider meaning that it is led by a poison or other toxic substance. Drug misuse and drug abuse also has different meanings according to the purpose of drug use. The former is defined by the use of a drug against its original purpose, and the latter is defined as the repetitive misuse of an addictive drug.

This paper reviews the common intoxications that are changing, and what the recent new modalities are in the management of intoxication in children and adolescents.

\section{EPIDEMIOLOGY}

Drug poisoning in the United States (US) was a leading cause of death [2], and 429.4 poisonings per 100,000 children was treated in hospital emergency

Received : December 4, 2013, Revised : December 16, 2013, Accepted : December 21, 2013

Corresponding author: Eell Ryoo, Department of Pediatrics, Gil Medical Center, Gachon University Graduate School of Medicine, 21 Namdongdaero 774 beon-gil, Namdong-gu, Incheon 405-760, Korea. Tel: +82-32-460-8905, Fax: +82-32-460-3224, E-mail: ryoo518@gilhospital.com

Copyright (c) 2013 by The Korean Society of Pediatric Gastroenterology, Hepatology and Nutrition

This is an open-access article distributed under the terms of the Creative Commons Attribution Non-Commercial License (http://creativecommons.org/licenses/by-nc/3.0/) which permits unrestricted non-commercial use, distribution, and reproduction in any medium, provided the original work is properly cited. 
departments in 2004 in spite of non-fatal poisonings in children younger than 5 years of age [3]. These were similar in Korean children from the results showing a decreasing death rate of younger childhood due to poisoning.

Death from poisoning in Korean children and adolescents has decreased since 1983 according to the national data collected by the Korean Statistical Office. Of the total death rate of 530.8/100,000 population, the death rate of children and adolescents below 19 years of age was 374.9/100,000 population in 2012. Although the death rate from unintentional causes has decreased slightly, the death rate from intentional exposure has increased due to suicidal attempts during adolescence. Suicide is the most common cause of teenage deaths and it has increased from $3.5 / 100,000$ population in 2002 to $5.5 / 100,000$ population in 2012. The increase in the death rate of teenagers from poisoning in Korea (1.7 to 3.3/ 100,000 population) was similar in the US according to the Centers for Disease Control and Prevention (CDC) data in 2000 to 2009 [4,5]. These results were explained partially by intentional teen poisoning.

A nationwide study based on the database from National Health Insurance Corporation and Statistics Korea in 1997 identified a male predominance of childhood poisoning [6]. But there has been conflicting results regarding the gender differences among other studies [6-10]. The age distribution of poisoning showed a bimodal pattern with the first peak in younger children and the second peak in adolescents among above studies [6-10]. The common cause of poisoning was different in the two periods. Although accidental exposure was the most common cause in younger children, suicidal attempts was the most common cause in adolescence [7-9]. This is similar to that reported in the US. From the reports of the American Association of Poison Control Centers' National Poison Data System (NPDS), intentional exposure was common in ages, 13-19 years, and this fatal exposure was caused by suicidal attempts [11].

In 1980s, poisoning by agricultural chemicals, such as insecticides, rodenticides and herbicides, were predominant at $37-52 \%$, but a gradual decreasing tendency was noted $[7,8]$. After the year 2000, the proportion of poisonings by agricultural chemicals was only $6-23 \%$. On the other hand, the proportion of medication poisonings increased to $31-57 \%$ compared to $14-17 \%$ in the 1980 s [7-10]. These increasing rates of poisoning by medication were noted regardless of regional areas. The other common causes of intoxication were hydrocarbons and personal care products. These were also noted in our unpublished studies (Fig. 1). These causative changes according to time in Korea were explained by some reasons such as, industrialization, decreasing use of agricultural chemicals, and the introduction of the national medical insurance system with increasing opportunities to come in contact with hospitals and pharmacies. These changes may have even changed with the establishment of the national poison information center since 2012 [12].

Above $50 \%$ drug intoxication were developed in children below 6 years of age. More than $90 \%$ of toxic

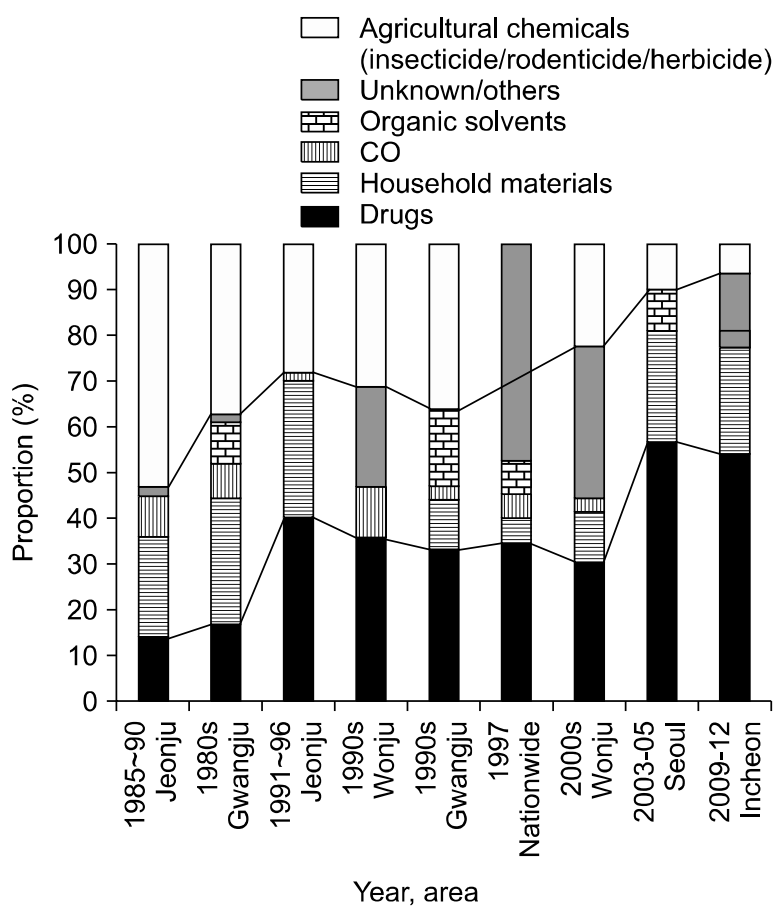

Fig. 1. Proportion of causative substances of drug intoxication according to the regional areas and years. CO: carbon monoxide. 
exposure in children occurred in the home. Most intoxications were caused by a single toxic substance, and the most common route was ingestion rather than via dermal, inhalational and ophthalmic exposure. Approximately 50\% of intoxications were caused by nondrug substances, such as cosmetics, personal care items, cleaning solutions, plants, and foreign bodies. Common pharmacological preparations were analgesics, topical preparations, cough and cold products, and vitamins. Therefore, $85 \%$ of exposures in children younger than 6 years of age can be managed without direct medical intervention, which means that most childhood intoxications are inherently non-toxic or minimally toxic [4,13-15]. On the other hand, in adolescence, which was second peak period of pediatric toxic exposure, most intoxications were intentional and often severely toxic with a high death rate in pediatric population (44/70 poison-related pediatric death $<19$ years old). The common substances of toxic exposure in adolescence are over-the-counter drugs, prescription medications and household products. According to the US reports in 2012, the proportion of poisonings by pharmaceutical agents was approximately $47 \%$ in children younger than 13 years of age [11].

\section{TOXIC AND NONTOXIC SUBSTANCES}

Table 1 lists the common nontoxic or minimally toxic substances $[13,14]$. Most of the substances encountered in the home are nontoxic or minimally toxic. On the other hand, some of the prescribed drugs are toxic, even at the minimal dose (Table 2) $[13,14,16,17]$.

\section{EVALUATION}

Although problem-oriented history taking is most important for evaluating patients with poisoning, special attention should be paid to children and adolescents with intentional exposure and without a witnessed exposure. When considering the time of ingestion, it will be better to overestimate the status of the patients. Toxidromes via vital signs and physical examinations are usually valuable for an appropriate laboratory evaluation and the prediction of ingested drugs. General laboratory tests are as follows; complete blood count, liver function test, urinalysis, serum and urine electrolytes, anion gap, and osmolarity, serum creatine kinase-MB (CK-MB), and coagulation time. If several types of intoxications, such as carbon monoxide (CO), acetaminophen, salicy-

Table 1. Common Nontoxic or Minimally Toxic Substances

\begin{tabular}{ll}
\hline Household products & Abrasives, candles, fabric softeners, incense \\
Medications & Antacid, antibiotics, antifungals, corticosteroids, calamine lotion, diaper rash cream \& ointments, \\
hydrogen peroxide $(3 \%)$, iodophil disinfectants, laxatives, oral contraceptives & Bath oil, body conditioners, cosmetics, hand lotions \& creams, soap, dish washing detergents, shampoo, \\
Personal care products & shaving cream, sunscreen (zinc oxide) \\
Stationary & Ballpoint pen ink, chalk, clay, crayons, glow products, glues, paste, indelible markers, ink, pencil lead, \\
water and oil colors & \\
Others & Fertilizers, fishbowl additives, plant food, silica, warfarin rodenticides $(<0.5 \%)$ \\
\hline
\end{tabular}

Table 2. Substances that Can Be Toxic to Children Even in Small Dose of Ingestion

\begin{tabular}{ll}
\hline Anti-malarials & Chloroquine, quinine, quinidine \\
Antipsychotics & Monoamine oxidase inhibitors, phenothiazines, tricyclic antidepressants \\
Cardiovascular agents & Atropine, $\beta$-blockers, calcium channel blockers, clonidine \\
Opioids & Diphenoxylate, lomotil, methadone, oxycodone, suboxone \\
Oral hypoglycemics & Sulfonylurea, meglitinides \\
Topical agents & Benzocaine, lindane \\
Others & Alcohol, camphor, hydrocarbon, nicotine, theophylline \\
\hline
\end{tabular}


Table 3. Methods for Evaluation of Toxicity and Prediction of Severity in Children and Adolescents with Poisoning

\begin{tabular}{ll}
\hline $\begin{array}{c}\text { Detailed history and } \\
\text { physical examination }\end{array}$ & $\begin{array}{c}\text { Consider toxidromes: } \\
\text { vital signs (temperature, blood pressure, and heart rate alterations, respiratory disturbances), } \\
\text { pupillary findings, skin findings, neuromuscular abnormalities, mental status alterations } \\
\text { Characteristic odors }\end{array}$ \\
& $\begin{array}{l}\text { Blood glucose, acid base status and anion gap with ABGA, serum electrolytes, osmolarity with osmolar } \\
\text { gap, BUN/Cr, liver function test, CPK with cardiac enzyme, coagulation test }\end{array}$ \\
& Urine dipstick test, urinalysis, pregnancy test (if needed) \\
& Quantitative drug serum concentration (e.g., acetaminophen, salicylate) \\
& Electrocardiogram \\
& Chest radiography \\
& Toxicologic screen (if needed)
\end{tabular}

ABGA: arterial blood gas analysis, BUN/Cr: Blood urea nitrogen and creatinine, CPK: creatine phosphokinase.

lates, anticonvulsants, iron, methanol, digoxin, and theophylline etc., are suspected, the quantitative blood concentrations are needed (Table 3). In addition, a toxicology screen must be done in the case of children who are neglected or abused $[13,14,17,18]$.

\section{MANAGEMENT}

Four principles, decontamination, enhanced elimination, antidotes and supportive care, are usually used in the management of intoxication [13]. Although the gastrointestinal decontamination is controversial, it will be effective after acute ingestion. Ipecac syrup has no longer been used in the US since the policy by the American Academy of Pediatrics (AAP) was released in 2003 [15]. Activated charcoal (AC) is used widely as the initial treatment because it acts as an adsorbent of toxic substances and can delay the absorption of toxins. With the exception of some poorly adsorbed substances, such as alcohols, caustics, hydrocarbons, iron etc., $\mathrm{AC}$ is one of the most useful agents of acute intoxication, particularly when administered within one hour after toxin ingestion [19].

The optimal dose of AC is not known, but the United States Pharmacopeia (USP, 2003) suggests the following: children up to one year of age, $10-25 \mathrm{~g}$ or $0.5-1.0 \mathrm{~g} / \mathrm{kg}$; children 1 to 12 years of age, $25-50 \mathrm{~g}$ or $0.5-1.0 \mathrm{~g} / \mathrm{kg}$; and adolescents, 25-100 g. Recently, whole-bowel irrigation with a large volume of polyethylene glycol electrolyte solution is used to man- age intoxication by slowly absorbing substances [20]. And this method has only minor side effects, such as transient adverse drug reactions, vomiting and abdominal pain.

To enhance the elimination of toxins, several methods, such as, multiple-dose AC, urinary alkalization, dialysis and antidotes, are available. Multipledose AC is only useful for some drugs [21], and others recommend this method restrictively [22]. In the case of intoxication by several drugs, antidotes are quite useful. These antidotes are listed in Table 4 $[13,14,17,18,23]$. In addition, supportive care is needed for intoxicated children and adolescents. A common form of intoxication that is rarely cited and being at issue and its management in children and adolescents is described in the following:

1. Caustics (sodium or potassium hydroxide, sodium hypochlorite, sodium carbonate, hydrochloric acid): Most alkali substances, which are more commonly ingested than acidic substances, are tasteless and are common in children less than 6 years of age. Esophageal strictures develop in approximately $20 \%$ of patients, and are not related to the extent of oropharyngeal injuries despite the proportional relationship with the presence of more symptoms. Therefore, endoscopy is needed to identify the stages of injury. In children, severe long-term complications including esophageal cancer can develop [13,18,24].

2. Plants: Because of the variable toxicity of the parts of plants, time of the year, growth conditions, route of exposure and variable common names ac- 
Table 4. Common Antidotes for Poisoning

\begin{tabular}{ll}
\hline \multicolumn{1}{c}{ Poison } & \multicolumn{1}{c}{ Antidote } \\
\hline Acetaminophen & N-acetylcysteine \\
Anticoagulant, rodenticides & Vitamin Kl \\
Anticholinergics & Physostigmine \\
Anti-malarials (chloroquine, quinine, quinidine) & Octreotide \\
Anti-psychotics (serotonin syndrome) & Dantrolene \\
Benzodiazepines & Flumazenil \\
$\beta$-Blocker & Glucagon \\
Calcium channel blocker & Glucagon, insulin, calcium salts \\
Carbon monoxide & Oxygen \\
Cyanide & Cyanide kit (amyl nitrate, sodium nitrate, sodium thiosulfate), \\
& hydroxocobalamin \\
Digitalis & Digoxin-specific Fab antibodies (Digibind; Digifab) \\
Ethylene glycol, methanol & Ethanol, fomepizole \\
Iron & Deferoxamine \\
Isoniazid & Pyridoxine \\
Lead and other heavy metals (arsenic, inorganic mercury) & BAL, CaNa ${ }^{2+}$-EDTA, DMSA \\
Lipophilic drugs: local anesthetics, amitriptyline, diltiazem, & 20\% lipid emulsion \\
bupropion, dosulepin, lamotrigine, quetiapine, and verapamil & \\
Methotrexate & Folic acid, leukovorin \\
Methemoglobinemia & Methylene blue, 1\% solution \\
Opioids & Naloxone \\
Oral hypoglycemic agents (sulfonylurea, other hyperinsulinemic & Dextrose, octreotide \\
agents) & \\
Organophosphates & Atropine, pralidoxime (2PAM) \\
Salicylates & Sodium bicarbonate \\
Tricyclic antidepressants & Sodium bicarbonate \\
Valproic acid & L-carnitine \\
\hline BAL Bition & \\
\hline
\end{tabular}

BAL: British anti-Lewisite, EDTA: edetate calcium disodium, DMSA: 2,3-dimercaptosuccinic acid (succimer).

cording to the region and countries, it is difficult to predict whether the plants would be toxic or nontoxic $[25,26]$. Therefore, it is important to communicate with the poison center or obtain information using smart phone applications [12,27].

3. Energy drinks: Since the introduction of energy drinks in Korea, 2010, they are becoming an object of public concern, particularly with adolescents. From the recent US data, accidental unintentional exposure in children less than 6 years of age is a major concern. In addition, almost one quarter of college students have consumed alcohol mixed with energy drinks [28]. This behavior is even more common in Korean college students with $49.3 \%$ than in the US. The mean caffeine content of 35 products in Korea is $67.94 \mathrm{mg}$, and each drink contains 30-175.8 mg of caffeine [29]. These are potentially dangerous because of the more concentrated volume of caffeine and the regular or mixed consumption with alcohol. The major adverse effects are vomiting, seizure, tachycardia, tachypnea, dysrhythmia, hypokalemia, hyperglycemia, and death [14,30,31]. No known specific antidotes are available, but benzodiazepines, beta-adrenergic blockers and lidocaine, are used according to the symptoms.

\section{CONCLUSION}

Pediatricians and physicians related to emergency departments should be aware of the changing causative substances of intoxication according to age and time. And precise history taking, through physical examination and current knowledge about care are needed for the proper and prompt management of intoxicated children and adolescents. Furthermore, all physicians must promote ways of preventing in- 
toxication and help to establish a nationwide poison control center.

\section{REFERENCES}

1. Wax PM. Historical principles and perspectives. In: Nelson LS, Lewin NA, Howland MA, Hoffman RS, Goldfrank LR, Flomenbaum NE, eds. Goldfrank's manual of toxicologic emergencies. New York: McGraw-Hill Companies, 2011:1-17.

2. Warner M, Chen LH, Makuc DM, Anderson RN, Miniño AM. Drug poisoning deaths in the United States, 1980-2008. NCHS Data Brief 2011;(81):1-8.

3. Franklin RL, Rodgers GB. Unintentional child poisonings treated in United States hospital emergency departments: national estimates of incident cases, population-based poisoning rates, and product involvement. Pediatrics 2008;122:1244-51.

4. Rossen LM, Khan D, Warner M. Trends and geographic patterns in drug-poisoning death rates in the U.S., 1999-2009. Am J Prev Med 2013;45:e19-25.

5. Statistics Korea. Causes of death [Internet]. Daejeon: Statistics Korea; 2012 [accessed 2013 Nov 20]. Available from: http://www.kostat.go.kr.

6. Park CS, Eun SH, Yang MH, Son JA, Hwang JY, Ko JW, et al. A study of acute poisoning in Korean children. Korean J Pediatr 2001;44:614-9.

7. Kim DK, Choi KC, Jung EK, Yang ES, Moon KR. The clinical study of acute poisoning in children. J Korean Pediatr Soc 1996;39:1753-8.

8. Kong HP, Park KB, Lee OK, Park KS. The statistical study of patient with acute poisoning. J Korean Pediatr Soc 1997;40:1596-602.

9. Eum JP, Suh JS, Kim HM. Clinical analysis of acute drug intoxication and foreign body ingestion in Wonju: comparison between the 1990 s and the 2000 s. Korean J Pediatr 2007;50:138-42.

10. Suh JH, Eo EK. The differences of clinical aspects in children and adolescents poisoning. J Korean Soc Clin Toxicol 2006:4;17-24.

11. Bronstein AC, Spyker DA, Cantilena LR Jr, Rumack BH, Dart RC. 2011 Annual report of the American Association of Poison Control Centers' National Poison Data System (NPDS): 29th Annual Report. Clin Toxicol (Phila) 2012;50:911-1164.

12. Poison Information Center. Introduction of poison information center [Internet]. Seoul: Poison Information Center; 2012 [accessed 2013 Mar 18]. Available from: http://www.poisoninfo.co.kr/ main.do.

13. O'Donnell KA, Ewald MB. Poisoning. In: Kliegman RM,
Stanton BF, St. Geme JW, Schor NF, Behrman RE, eds. Nelson textbook of pediatrics. Philadelphia, PA: Elsevier Saunders, 2011:250-301.

14. Barrueto F Jr, Gattu R, Mazer-Amirshahi M. Updates in the general approach to the pediatric poisoned patient. Pediatr Clin North Am 2013;60:1203-20.

15. Ressel GW; AAP. AAP releases policy statement on poison treatment in the home. Am Fam Physician 2004;69:741-2.

16. Singer J, Janz T. Apnea and seizures caused by nicotine ingestion. Pediatr Emerg Care 1990;6:135-7.

17. Tintinalli JE, Stapczynski JS. Tintinalli's emergency medicine: a comprehensive study guide. New York: McGraw-Hill, 2011.

18. Goldfrank LR, Hoffman RS. Goldfrank's manual of toxicologic emergencies. New York: McGraw-Hill Medical, 2007.

19. Chyka PA, Seger D, Krenzelok EP, Vale JA; American Academy of Clinical Toxicology; European Association of Poisons Centres and Clinical Toxicologists. Position paper: Single-dose activated charcoal. Clin Toxicol (Phila) 2005;43:61-87.

20. Lo JC, Ubaldo C, Cantrell FL. A retrospective review of whole bowel irrigation in pediatric patients. Clin Toxicol (Phila) 2012;50:414-7.

21. Burns MM. Activated charcoal as the sole intervention for treatment after childhood poisoning. Curr Opin Pediatr 2000;12:166-71.

22. Eddleston M, Juszczak E, Buckley NA, Senarathna L, Mohamed F, Dissanayake W, et al; Ox-Col Poisoning Study collaborators. Multiple-dose activated charcoal in acute self-poisoning: a randomised controlled trial. Lancet 2008;371:579-87.

23. Presley JD, Chyka PA. Intravenous lipid emulsion to reverse acute drug toxicity in pediatric patients. Ann Pharmacother 2013;47:735-43.

24. Kay M, Wyllie R. Caustic ingestions in children. Curr Opin Pediatr 2009;21:651-4.

25. Kim C, Kim DS, Lee HW, Ahn YM, Uhm JH. A case of grayanotoxin intoxication presenting with mental changes and vomiting. Korean J Pediatr Gastroenterol Nutr 2008;11:223-5.

26. Kwak BO, Bae SH. A case of hyperacute liver failure from mushroom intoxication in a child treated with penicillin. Korean J Pediatr Gastroenterol Nutr 2008;11:210-3.

27. Asan Medical Center. Korean wild plants [Internet]. Seoul: Asan Medical Center; 2011 [accessed Mar 14, 2013]. Available from: https://itunes. apple.com/kr/app/hangug-ui-yasaengsigmul/id416043 873? $\mathrm{mt}=8$.

28. O'Brien MC, McCoy TP, Rhodes SD, Wagoner A, 
Wolfson M. Caffeinated cocktails: energy drink consumption, high-risk drinking, and alcohol-related consequences among college students. Acad Emerg Med 2008;15:453-60.

29. Lim HO. Energy drink safety condition investigation [Internet]. Seoul: Korea Consumer Agency; 2013 [accessed 2013 Nov 15]. Available from: https://www. kca.go.kr/modules/board/view.jsp?\&boardConfigNo=
$154 \&$ menuNo=307\&boardNo=38067.

30. Seifert SM, Seifert SA, Schaechter JL, Bronstein AC, Benson BE, Hershorin ER, et al. An analysis of energy-drink toxicity in the National Poison Data System. Clin Toxicol (Phila) 2013;51:566-74.

31. Wolk BJ, Ganetsky M, Babu KM. Toxicity of energy drinks. Curr Opin Pediatr 2012;24:243-51. 